\title{
Retraction
}

\section{Retraction: De Vecchis, R., et al. Platypnea-Orthodeoxia Syndrome: Multiple Pathophysiological Interpretations of a Clinical Picture Primarily Consisting of Orthostatic Dyspnea. J. Clin. Med. 2016, 5, 85}

\author{
Renato De Vecchis ${ }^{1, *(D)}$, Cesare Baldi ${ }^{2}$, Carmelina Ariano ${ }^{1}$ and JCM Editorial Office ${ }^{3}$ \\ 1 Cardiology Unit, Presidio Sanitario Intermedio "Elena d'Aosta”, ASL Napoli 1 Centro, 80137 Napoli, Italy; \\ carmelariano@tiscali.it \\ 2 Heart Department, Interventional Cardiology, Azienda Ospedaliero-Universitaria "San Giovanni di Dio e \\ Ruggi d'Aragona", 84131 Salerno, Italy; giovenale80@gmail.com \\ 3 MDPI, St. Alban-Anlage 66, 4052 Basel, Switzerland; jcm@mdpi.com \\ * Correspondence: devecchis.erre@virgilio.it
}

Citation: De Vecchis, R.; Baldi, C.; Ariano, C.; JCM Editorial Office. Retraction: De Vecchis, R., et al. Platypnea-Orthodeoxia Syndrome: Multiple Pathophysiological Interpretations of a Clinical Picture Primarily Consisting of Orthostatic Dyspnea. J. Clin. Med. 2016, 5, 85. J. Clin. Med. 2021, 10, 883. https:// doi.org/10.3390/jcm10040883

Received: 11 November 2020 Accepted: 4 February 2021

Published: 22 February 2021

Publisher's Note: MDPI stays neutral with regard to jurisdictional claims in published maps and institutional affiliations.

Copyright: (c) 2021 by the authors. Licensee MDPI, Basel, Switzerland. This article is an open access article distributed under the terms and conditions of the Creative Commons Attribution (CC BY) license (https:// creativecommons.org/licenses/by/ $4.0 /)$.
The journal retracts the article "Platypnea-Orthodeoxia Syndrome: Multiple Pathophysiological Interpretations of a Clinical Picture Primarily Consisting of Orthostatic Dyspnea" by De Vecchis, R., et al. [1].

Following publication, concerns were brought to the attention of the publisher regarding an alleged redundant publication with "Platypnea-orthodeoxia Syndrome: Orthostatic Dyspnea and Possible Pathophysiological Substrates" by De Vecchis, R., et al. [2].

Adhering to our complaints procedure, an investigation was conducted that confirmed the existence of a redundant publication and the article is therefore retracted.

This retraction was approved by the Editor-in-Chief of Journal of Clinical Medicine.

The authors agreed to this retraction.

\section{References}

1. De Vecchis, R.; Baldi, C.; Ariano, C. Platypnea-Orthodeoxia Syndrome: Multiple Pathophysiological Interpretations of a Clinical Picture Primarily Consisting of Orthostatic Dyspnea. J. Clin. Med. 2016, 5, 85. [CrossRef] [PubMed]

2. De Vecchis, R.; Baldi, C.; Ariano, C.; Giasi, A.; Cioppa, C. Platypnea-orthodeoxia Syndrome: Orthostatic Dyspnea and Possible Pathophysiological Substrates. Herz 2017, 42, 384-389. [CrossRef] [PubMed] 